(C) 2021, The Authors. Published by Elsevier Inc. and Fass Inc. on behalf of the American Dairy Science Association ${ }^{\circledR}$. This is an open access article under the CC BY-NC-ND license (http://creativecommons.org/licenses/by-nc-nd/4.0/).

\title{
Preweaning nutrient supply alters serum metabolomics profiles related to protein and energy metabolism and hepatic function in Holstein heifer calves
}

\author{
L. N. Leal, ${ }^{1 *} \odot$ J. Doelman, ${ }^{1} \odot$ B. R. Keppler, ${ }^{2} \odot$ M. A. Steele, ${ }^{3} \odot$ and J. Martín-Tereso ${ }^{1} \odot$ \\ ${ }^{1}$ Trouw Nutrition Research and Development, P.O. Box 299, 3800 AG, Amersfoort, the Netherlands \\ ${ }^{2}$ Department of Discovery and Translational Sciences, Metabolon Inc., Morrisville, NC 27560 \\ ${ }^{3}$ Department of Animal Bioscience, Animal Science and Nutrition, University of Guelph, Guelph, ON N1G 1Y2, Canada
}

\begin{abstract}
Lifting the preweaning milk restriction in dairy calves has been causally associated with beneficial effects on growth and future lactation performance. However, the biological mechanisms linking early-life nutrient supply and future performance remain insufficiently understood. Thus, the objective of this study was to characterize growth and the metabolic profiles of calves fed a restricted (RES) and an elevated (ELE) milk supply preweaning. A total of 86 female Holstein Friesian calves were blocked in pairs by maternal parity and received identical colostrum supply within block. Treatments randomized within block consisted of a milk replacer (MR; $24 \%$ crude protein, $18 \%$ crude fat, and $45 \%$ lactose) supplied at either $5.41 \mathrm{Mcal}$ of ME in $8 \mathrm{~L}$ of MR/d (ELE) or $2.71 \mathrm{Mcal}$ of ME in $4 \mathrm{~L}$ of MR/d (RES) from d 2 after birth until they were stepped down by $50 \%$ during wk 7 and fully weaned at wk 8 . All calves had ad libitum access to pelleted calf starter (17.3\% crude protein, $24.4 \%$ neutral detergent fiber, $2.0 \%$ crude fat, and $18.2 \%$ starch), chopped wheat straw, and water. At 2 and $49 \mathrm{~d}$ of age, blood samples were taken for metabolomics analysis. The ELE group by design consumed more milk replacer, resulting in a lower starter intake and a greater body weight and average daily gain. The ELE calves consumed 20.7\% more ME and 9.7\% more crude protein. However, efficiency of growth was not different between groups. Metabolomic profiling using 908 identified metabolites served to characterize treatment-dependent biochemical differences. Principal component analysis revealed clearly distinct metabolic profiles at $49 \mathrm{~d}$ of age in response to preweaning milk supply. Changes in energy (fatty acid metabolism and tricarboxylic acid metabolites), protein (free AA, dipeptides, and urea cycle),
\end{abstract}

Received November 3, 2020.

Accepted March 20, 2021.

*Corresponding author: leonel.leal@trouwnutrition.com and liver metabolism (bile acid and heme metabolism) were the main effects associated with the dietary differences. The ELE group consumed proportionately more glucogenic nutrients via milk replacer, whereas the RES group consumed proportionately more ketogenic nutrients from the digestion of the calf starter, comprising a larger portion of total intake. Associated with the higher growth rate of the ELE group, hepatic changes were expressed as differences in bile acid and heme metabolism. Furthermore, energy metabolism differences were noted in fatty acid and AA metabolism and the urea cycle. The metabolic profile differences between the ELE and RES groups reflect the broad differences in nutrient intake and diet composition and might point to which metabolic processes are responsible for greater dairy performance for cows fed a greater milk supply preweaning.

Key words: metabolomics, calf, preweaning nutrition, milk replacer

\section{INTRODUCTION}

Restricting whole milk or milk replacer (MR) supply in early life limits the growth of the neonatal dairy calf. Conventional practice is provision of milk or MR at about $10 \%$ of calf BW in 2 feedings. However, evidence indicates that calf growth and feed efficiency could be improved by feeding greater amounts of whole milk or MR before weaning (Diaz et al., 2001; Jasper and Weary, 2002). Additionally, an elevated level of nutrient intake enables heifers to achieve breeding size and maturity earlier, potentially decreasing age at first calving and reducing rearing costs of replacement heifers (Radcliff et al., 2000; Raeth-Knight et al., 2009; Davis Rincker et al., 2011). Previous research has also shown that increasing nutrient supply by lifting conventional milk restriction from birth up to $56 \mathrm{~d}$ resulted in increased milk yield during first lactation, ranging from 450 to 1,400 kg (Foldager and Krohn, 1994; Bar-Peled et al., 1997; Soberon et al., 2012). 
The mechanisms by which enhanced early-life nutrition improves performance at maturity are insufficiently understood. However, in biology there are many examples in which nutritional interventions or insults in early development phases result in long-lasting changes in morphological and metabolic development. The association between early-life nutrition and health on long-term disease outcomes is described in humans (Lucas, 1991; Eriksson et al., 2003; Ness, 2004), rats (Delamaire et al., 2012), pigs (Boubred et al., 2017), and sheep (Berry et al., 2016). Hanley et al. (2010) reviewed data suggesting that undernutrition in early life influences the development of metabolic and cardiovascular disease, neurodevelopment, obesity, and bone health. Although most data supporting this idea in humans are not causal, they indicate a strong association between early-life nutrition and health at later phases of life.

Metabolomics is the identification and study of biochemical compounds used to describe the metabolite complement of living tissues (Oliver et al., 1998). One principal analytical approach, the identification of metabolite profiles (Hall, 2006), is a suitable tool to determine metabolic differences in groups of animals. Suitable biomarkers remain to be identified in neonatal dairy calves to reflect the biological status at a given time but are also predictive of a later effect and remain measurable after a period of time or nutritional intervention.

The present study aimed to characterize the metabolome of neonatal dairy heifers at d 2 of life and before weaning at d 49 under 2 distinct nutrient supply regimens that are expected to prime them for differences later in life. We used metabolomics profiling in conjunction with intake and growth parameters with the objective of identifying the main metabolic pathways associated with greater growth in neonatal calves fed twice as much milk preweaning.

\section{MATERIALS AND METHODS}

\section{Animals, Diets, and Treatments}

All procedures complied with the Dutch Law on Experimental Animals and the ETS123 (council of Europe 1985 and the 86/609/EEC Directive) and were approved by the Animal Care and Use Committee of Utrecht University.

Eighty-six Holstein heifer calves born at the Trouw Nutrition Dairy Research Facility (Boxmeer, the Netherlands) from February 2014 through August 2015 were enrolled in this study. Calves were housed in individual outdoor hutches $(1.07 \times 1.60 \mathrm{~m})$ bedded with wheat straw and outfitted with a metal roof attachment to
Table 1. Analyzed and estimated nutrient composition ( $\mathrm{g} / \mathrm{kg}$ of DM unless otherwise noted) of milk replacer, starter feed, and straw used in the study

\begin{tabular}{lccc}
\hline Item & $\begin{array}{c}\text { Milk } \\
\text { replacer }^{1}\end{array}$ & $\begin{array}{c}\text { Calf } \\
\text { starter }^{2}\end{array}$ & Straw \\
\hline DM, g/kg of product & 976 & 888 & 927 \\
CP & 247 & 195 & 37 \\
Ether extract & 188 & 23 & 12 \\
Lactose & 458 & - & - \\
Ash & 82 & 81 & 73 \\
Starch & - & 205 & - \\
NDF & - & 275 & 730 \\
ADF & - & 142 & 536 \\
ME, ${ }^{3}$ Mcal/kg of DM & 4.62 & 2.85 & 1.28 \\
\hline
\end{tabular}

${ }^{1}$ Ingredient composition: $50 \%$ skim milk powder, $20 \%$ sweet whey powder, $11 \%$ palm oil, $6 \%$ coconut oil, $11 \%$ delactosed whey powder, and $2 \%$ premix.

${ }^{2}$ Ingredient composition: $25 \%$ soybean meal, $20 \%$ corn, $15 \%$ soybean hulls, $10.5 \%$ alfalfa, $10 \%$ barley, $10 \%$ beet pulp, $5 \%$ beet molasses, $1 \%$ soybean oil, $1 \%$ limestone, $1 \%$ monocalcium phosphate, and $1.5 \%$ premix.

${ }^{3}$ Calculated using equations in NRC (2001).

protect the feed and water from precipitation until 70 d of life.

All calves received $4 \mathrm{~L}$ of pasteurized colostrum within $6 \mathrm{~h}$ after birth, either with a bottle in 2 feedings of $2 \mathrm{~L}$ each at 1 and $6 \mathrm{~h}$ after birth (56 calves) or with an esophageal tube in 1 feeding of $4 \mathrm{~L} 1 \mathrm{~h}$ after birth (30 calves). Calves were blocked in pairs by birth sequence and parity of the dam (primiparous vs. multiparous). Calves in the same block received an equal colostrum supply by pooling colostrum from different dams and preparing colostrum doses that were equal in quality ( $\geq 22 \%$ Brix), composition, and protocol of supply. Within block, calves were randomly assigned to 1 of 2 treatments: $5.14 \mathrm{Mcal}$ of ME in $8 \mathrm{~L}$ of MR/d (150 $\mathrm{g} / \mathrm{L} ; 1,200 \mathrm{~g} / \mathrm{d}$ ) for an elevated level of nutrient intake $(\mathbf{E L E} ; \mathrm{n}=43)$ or $2.71 \mathrm{Mcal}$ of ME in $4 \mathrm{~L}$ of MR/d (150 $\mathrm{g} / \mathrm{L} ; 600 \mathrm{~g} / \mathrm{d}$ of $\mathrm{MR}$ powder) for a restricted level of nutrient intake $(\mathbf{R E S} ; \mathrm{n}=43)$. Milk replacer composition is detailed in Table 1.

The MR feeding program began at $2 \mathrm{~d}$ of age and was concluded after a step-down reduction of the amount of MR in each meal by $50 \%$ from d 49 until d 56 . Restricted calves immediately began their treatment at d 2 of age $(2.71 \mathrm{Mcal}$ of $\mathrm{ME} / \mathrm{d}$ in 2 meals of $2 \mathrm{~L}$ ). Nutrient supply to calves in the ELE treatment was gradually increased in the first week of life, consisting of $3.38 \mathrm{Mcal}$ of $\mathrm{ME} / \mathrm{d}$ (in 2 meals of $2.5 \mathrm{~L}$ ) on d 2 and 3, $4.46 \mathrm{Mcal}$ of ME/d (in 2 meals of $3.0 \mathrm{~L}$ ) on d 4 and 5 , and $4.73 \mathrm{Mcal}$ of ME/d (in 2 meals of $3.5 \mathrm{~L}$ ) on d 6 and 7. From d 8 onward, calves were offered 5.41 Mcal of $\mathrm{ME} / \mathrm{d}$ (in 2 meals of $4.0 \mathrm{~L}$ ).

During the treatment period, MR was fed at approximately 0700 and $1700 \mathrm{~h}$ via a nipple bucket. Calves were given ad libitum access to water, fresh calf starter, 
and wheat straw (Table 1), each provided in separate buckets at the front of the hutch at morning milk feeding $(0700 \mathrm{~h})$.

\section{Intake, Body Measurements, and Blood Sampling}

The individual daily intakes of MR, starter, straw, and water were recorded until $70 \mathrm{~d}$ of age. Calves were weighed at birth and at d 2, 7, 14, 21, 28, 35, 42, 49, 56,63 , and 70 . All weights were taken approximately 3 $\mathrm{h}$ after the morning milk supply.

Blood samples were collected via jugular venipuncture into 10-mL potassium EDTA Vacutainers (Becton Dickinson) before the first milk feeding on d 2 and 49 . All blood samples were centrifuged immediately after collection at $2,800 \times g$ for $30 \mathrm{~min}$ at room temperature, and $1.5 \mathrm{~mL}$ of serum was pipetted into four 2-mL cryotubes and stored at $-80^{\circ} \mathrm{C}$.

\section{Metabolomics Analysis}

Serum metabolome analysis was performed on samples from 25 complete blocks ( 25 calves per treatment; 50 calves total) taken on d 2 and 49. Samples were stored at $-80^{\circ} \mathrm{C}$ until processed as described previously (Evans et al., 2009) at Metabolon Inc. (Durham, NC). Briefly, recovery standards were added before the first step in the extraction process for quality control purposes. To remove protein, dissociate small molecules bound to protein or trapped in the precipitated protein matrix, and recover chemically diverse metabolites, proteins were precipitated with methanol under vigorous shaking for 2 min (GenoGrinder 2000, Glen Mills Inc.) followed by centrifugation. The resulting extract was divided into 5 fractions: 2 for analysis by 2 separate reverse-phase ultra-performance liquid chromatography (UPLC)-tandem MS methods with positive ion mode electrospray ionization (ESI), 1 for analysis by reversephase UPLC-tandem MS with negative ion mode ESI, 1 for analysis by hydrophilic interaction chromatography/UPLC-tandem MS with negative ion mode ESI, and 1 reserved for backup. Three types of controls were analyzed in concert with the experimental samples. First, a pooled matrix sample was generated by taking a small volume of each experimental sample or, alternatively, use of a pool of human plasma characterized by Metabolon Inc., which served as a technical replicate throughout the data set. Second, extracted water samples served as process blanks. Third, a cocktail of quality control standards that were spiked into every analyzed sample allowed instrument performance monitoring and aided chromatographic alignment. Instrument variability was determined by calculating the median relative standard deviation (RSD) for the standards that were added to each sample before injection into the mass spectrometers (median RSD typically $4-6 \%$ when $\mathrm{n} \geq 30$ samples). Overall process variability was determined by calculating the median RSD for all endogenous metabolites (i.e., noninstrument standards) present in $100 \%$ of the pooled matrix samples. Experimental samples were randomized across the platform run, with quality control samples spaced evenly among the injections.

\section{MS Analysis}

All analytical methods used a Waters Acquity UPLC and a Thermo Scientific Q-Exactive high resolution/ accurate mass spectrometer interfaced with a heated electrospray ionization source and Orbitrap mass analyzer operated at 35,000 mass resolution. The sample extract was dried and then reconstituted in solvents compatible with each of the 4 methods described below. Each reconstitution solvent contained a series of standards at fixed concentrations to ensure injection and chromatographic consistency. One aliquot was analyzed using acidic positive ion conditions, chromatographically optimized for more hydrophilic compounds. In this method, the extract was gradient eluted from a C18 column (Waters UPLC BEH C18, $2.1 \times 100 \mathrm{~mm}$, $1.7 \mu \mathrm{m})$ using water and methanol, containing $0.05 \%$ perfluoropentanoic acid and $0.1 \%$ formic acid. Another aliquot was analyzed using acidic positive ion conditions; however, it was chromatographically optimized for more hydrophobic compounds. In this method, the extract was gradient eluted from the aforementioned C18 column using methanol, acetonitrile, water, $0.05 \%$ perfluoropentanoic acid, and $0.01 \%$ formic acid and was operated at an overall higher organic content. Another aliquot was analyzed using basic negative ion optimized conditions using a separate dedicated $\mathrm{C} 18$ column. The basic extracts were gradient eluted from the column using methanol and water, with $6.5 \mathrm{mM}$ ammonium bicarbonate at $\mathrm{pH} 8$. The fourth aliquot was analyzed via negative ionization following elution from a hydrophilic interaction chromatography column (Waters UPLC $\mathrm{BEH}$ amide, $2.1 \times 150 \mathrm{~mm}, 1.7 \mu \mathrm{m})$ using a gradient consisting of water and acetonitrile with $10 \mathrm{~m} M$ ammonium formate at $\mathrm{pH}$ 10.8. The MS analysis alternated between MS and data-dependent $\mathrm{MS}^{\mathrm{n}}$ (multiple stages of MS) scans using dynamic exclusion. The scan range covered 70 to $1,000 \mathrm{~m} / \mathrm{z}$.

\section{Compound Identification, Quantification, and Data Curation}

Raw data were extracted, peak identified, and quality control processed using Metabolon's hardware and 
software. Compounds were identified by comparison with library entries of purified standards or recurrent unknown entities. The quality control and curation processes were designed to ensure accurate and consistent identification of true chemical entities and to remove those representing system artifacts, misassignments, and background noise. Metabolon maintains a library based on authenticated standards that contains the retention time and index, mass:charge ratio, and chromatographic data (including tandem MS spectral data) on all molecules present in the library. More than 3,300 commercially available purified standard compounds have been acquired and registered into a laboratory information management system for analysis on all platforms for determination of their analytical characteristics. Peaks were quantified using area under the curve, and each compound was corrected in run-day blocks by registering the medians to equal 1.00 and normalizing each data point proportionately.

\section{Statistical and Mathematical Calculations}

Performance measurements such as BW, ADG, feed intake, and efficiency were calculated and analyzed as a single consolidated measurement per week. The predicted ME intake was calculated as the product of DMI of the total diet times the ME content in the offered feed.

To examine the effect of treatment, data were analyzed as repeated measures using a mixed-effect model procedure in SAS (PROC MIXED; SAS 9.3, SAS Institute Inc.) that accounted for the fixed effects of treatment, age of measurement, and their 2-way interaction and the random effect of block. Age entered the model as the repeated term, and an autoregressive type 1 covariance structure was used. Differences between treatments at different ages were determined using the LSMEANS SLICE statement.

The biochemical profiles of serum samples from 50 calves were analyzed using repeated-measures ANOVA and principal component analysis on natural logtransformed data in ArrayStudio (OmicSoft ArraySuite 10.0, Qiagen N.V.). Significance was declared when $P$ $<0.05$, and trends were declared when $0.05 \leq P<$ 0.10 .

\section{RESULTS}

\section{Animal Performance and Nutrient Intake}

Calves on the ELE treatment consumed more MR (by design; Figure 1A) and less starter (Figure 1B) and water (Supplemental Figure S1, http://dx.doi.org/10 .17632/wb7v54r2p4.1; Leal, 2021a) compared with the RES calves for the duration of the study $(P<0.001)$. In the first $4 \mathrm{wk}$, the ELE group acclimated to the higher amounts of MR and thereafter consumed the full $8 \mathrm{~L}$ (1,200 g of powder/d). From wk 4 onward, RES calves consumed 1.7 times more starter than the ELE group $(P<0.01)$. The evolution of ME intake is presented in Figure 1C. The ELE group consumed more ME from wk 1 to $7(P<0.01)$, although at weaning (wk 8) and thereafter the RES group consumed more ME $(P<0.01)$.

Initial BW was similar $(40.6 \pm 0.84 \mathrm{~kg})$, but ELE calves immediately became heavier from wh 1 to $10(P$ $<0.01$; Figure 2A). Their ADG was greater from wk 1 to 5 and wk $10(P<0.01)$ but lower on wk 8 and 9 $(P<0.01)$ and overall greater from wk 1 to $10(P<$ 0.01 ; Figure $2 \mathrm{~B}$ ). Feed efficiency, defined as gain:ME, is presented in Figure 2C. The ELE calves demonstrated higher efficiency on wk 1,2 , and $10(P<0.01)$, whereas RES calves were more efficient than ELE calves on wk $6,7,8$, and $9(P<0.01)$. However, overall efficiency was not affected by the dietary treatments $(P=0.661)$.

\section{Principal Component Analysis and Statistical Summary}

Principal component analysis revealed very distinct metabolic profiles by time and level of nutrient intake (Figure 3). As depicted in the statistical summary, at least $84.7 \%$ of biochemicals changed with time (d 2 vs. d 49), whereas $46.9 \%$ changed relative to treatment at d 49. Three main biological processes were predicted to be affected by the 2 treatment groups: liver metabolism, energy metabolism, and protein metabolism.

\section{Energy Metabolism-Associated Changes to Level of Nutrient Intake}

Nutrient intake levels produced clear differences in circulating fatty acids, fatty acid metabolism, and tricarboxylic acid cycle (Figure 4). Calves on the ELE diet presented lower levels $(P<0.05)$ of circulating long-chain fatty acids (LCFA), such as pentadecanoate, margarate, 10-heptadecenoate, nonadecanoate, 10-nonadecenoate, and PUFA, such as eicosapentaenoate, docosapentaenoate, docosahexaenoate, linolenate, dihomo-linolenate, dihomo-linoleate, and mead acid. In terms of fatty acid metabolism at $\mathrm{d} 49$, calves on the ELE treatment show increased carnitine (1.2-fold) and acyl-carnitines (acetyl-, succinyl-, hexanoyl-, octanoyl-, decanoyl-, lauryl-, myristoyl-, palmitoyl-, oleoyl-, and 
A
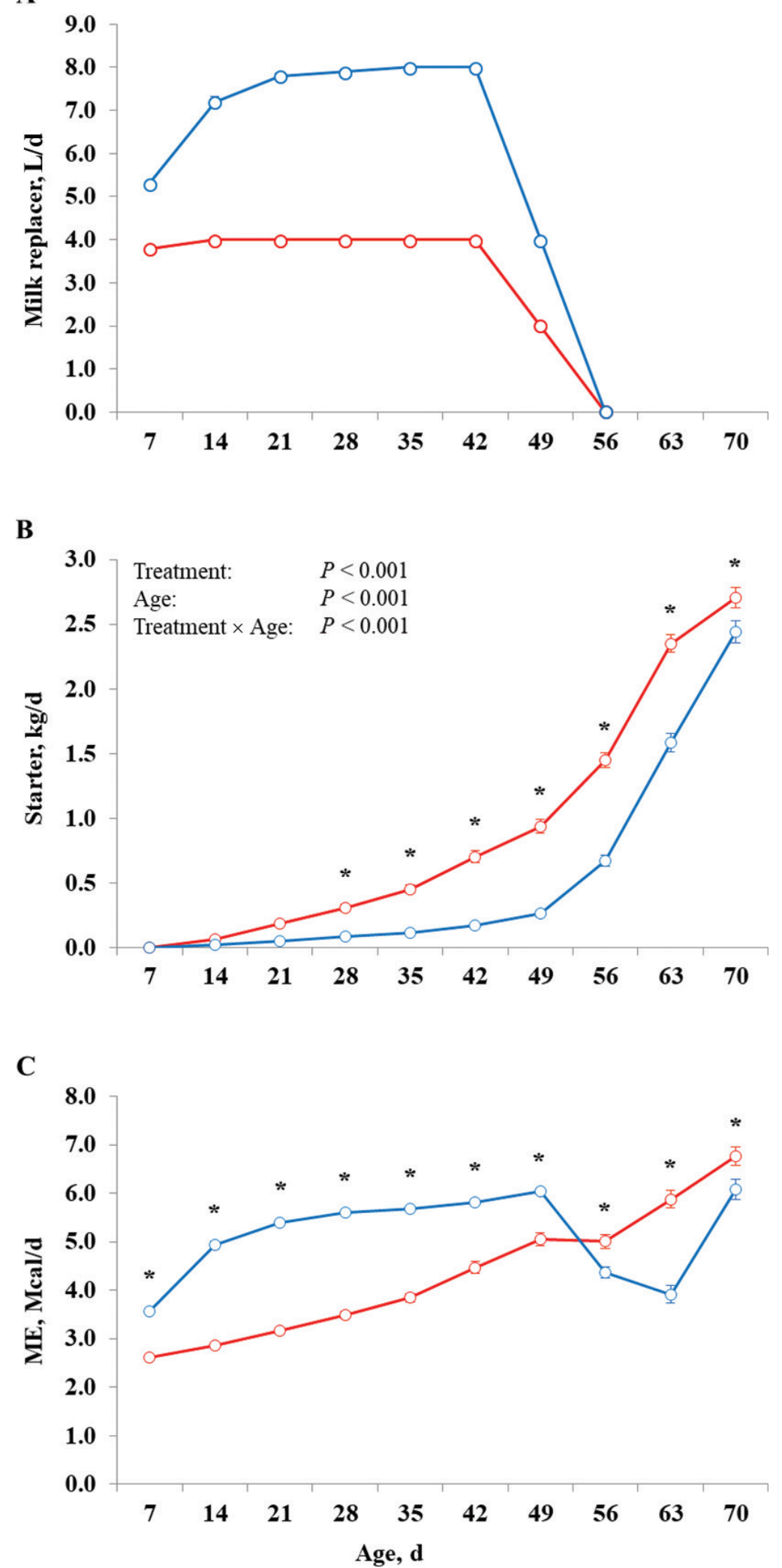

Figure 1. Summary of mean (A) milk replacer intake (L/d), (B) starter feed intake ( $\mathrm{kg} / \mathrm{d})$, and (C) ME intake (Mcal/d) of dairy calves (n $=86$ ) fed a restricted (red) or elevated (blue) level of nutrient intake. Asterisks indicate differences $(P<0.05)$ between the 2 treatments. Error bars indicate SE. 


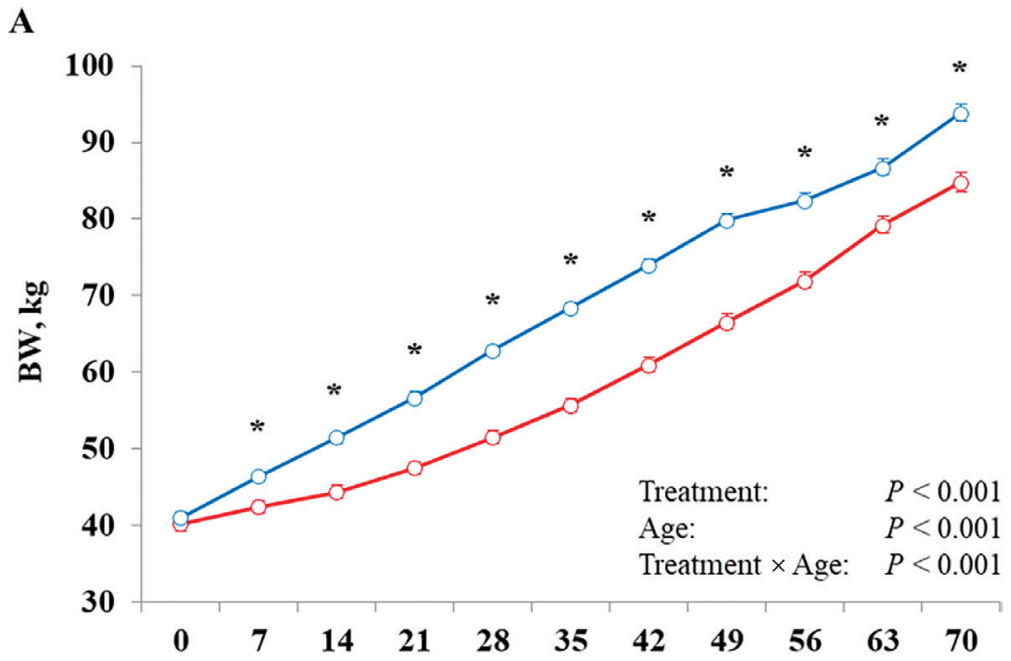

B
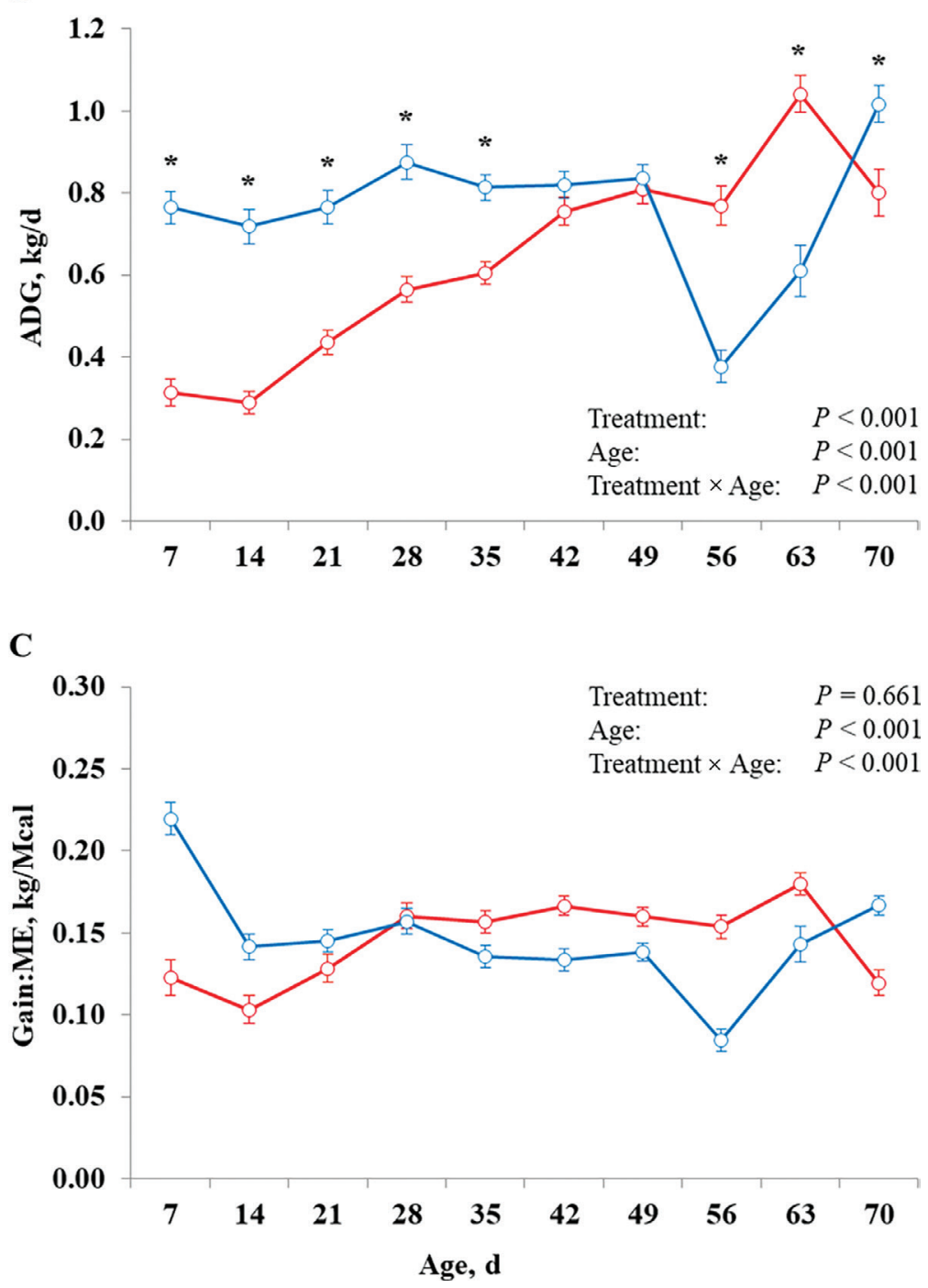

Figure 2. Development of mean (A) BW $(\mathrm{kg}),(\mathrm{B}) \mathrm{ADG}(\mathrm{kg} / \mathrm{d})$, and $(\mathrm{C})$ gain:ME $(\mathrm{kg} / \mathrm{Mcal})$ of dairy calves $(\mathrm{n}=86)$ fed a restricted $(\mathrm{red})$ or elevated (blue) level of nutrient intake. Asterisks indicate differences $(P<0.05)$ between the 2 treatments. Error bars indicate SE. 
myristoleoyl-). Of interest, $\mathrm{BHB}$, an end product of acetyl-CoA incomplete oxidation, in serum of ELE calves was lower $(P<0.05)$ than that in serum of RES calves. Finally, the current analysis also revealed that ELE feeding for d 49 led to a reduction $(P<0.05)$ in tricarboxylic acid cycle intermediates and metabolites (succinate, fumarate, malate, tricarballylate, and 2-methylcitrate).

\section{Protein Metabolism-Associated Metabolic Changes to Level of Nutrient Intake}

Calves fed the ELE diet had higher $(P<0.05)$ circulating AA (serine, threonine, glutamate, glutamine, lysine, tyrosine, tryptophan, methionine, cysteine, proline, and arginine) and dipeptides (glycylvaline, isoleucylglycine, phenylalanylalanine, valylglutamine, and valylglycine; Figure 5). Moreover, calves fed the ELE diet registered higher levels of homoarginine (1.70-fold) and homocitrulline (1.32-fold) and lower levels of urea (0.85-fold) and citrulline (0.84-fold; $P<0.05)$.

\section{Liver-Associated Metabolite Changes to Level of Nutrient Intake}

As presented in Figure 6, liver-associated changes were largely composed of differences in bile acids and heme metabolism. The analysis revealed that consumption of the ELE diet led to an increase in primary bile acids, such as glycochenodeoxycholate, taurochenodeoxycholate, tauro- $\alpha$-muricholate, and tauro- $\beta$-muricholate, and in the secondary bile acid metabolites taurolithocholate, taurolithocholate 3-sulfate, ursodeoxycholate, glycoursodeoxycholate, tauroursodeoxycholate, and taurocholenate sulfate. On the other hand, ELE feeding led to a reduction $(P<0.05)$ in cholate, glycocholate, chenodeoxycholate, deoxycholate, glycodeoxycholate, lithocholate, glycolithocholate, glycolithocholate sulfate, 3-dehydrocholate, and 7-ketodeoxycholate. Meanwhile, nutrient intake levels also induced significant alterations in heme metabolism. Calves fed an ELE diet had higher levels $(P<0.05)$ of heme $(1.55$-fold $)$, bilirubin [1.22-fold, Z,Z (Z indicates the higher priority

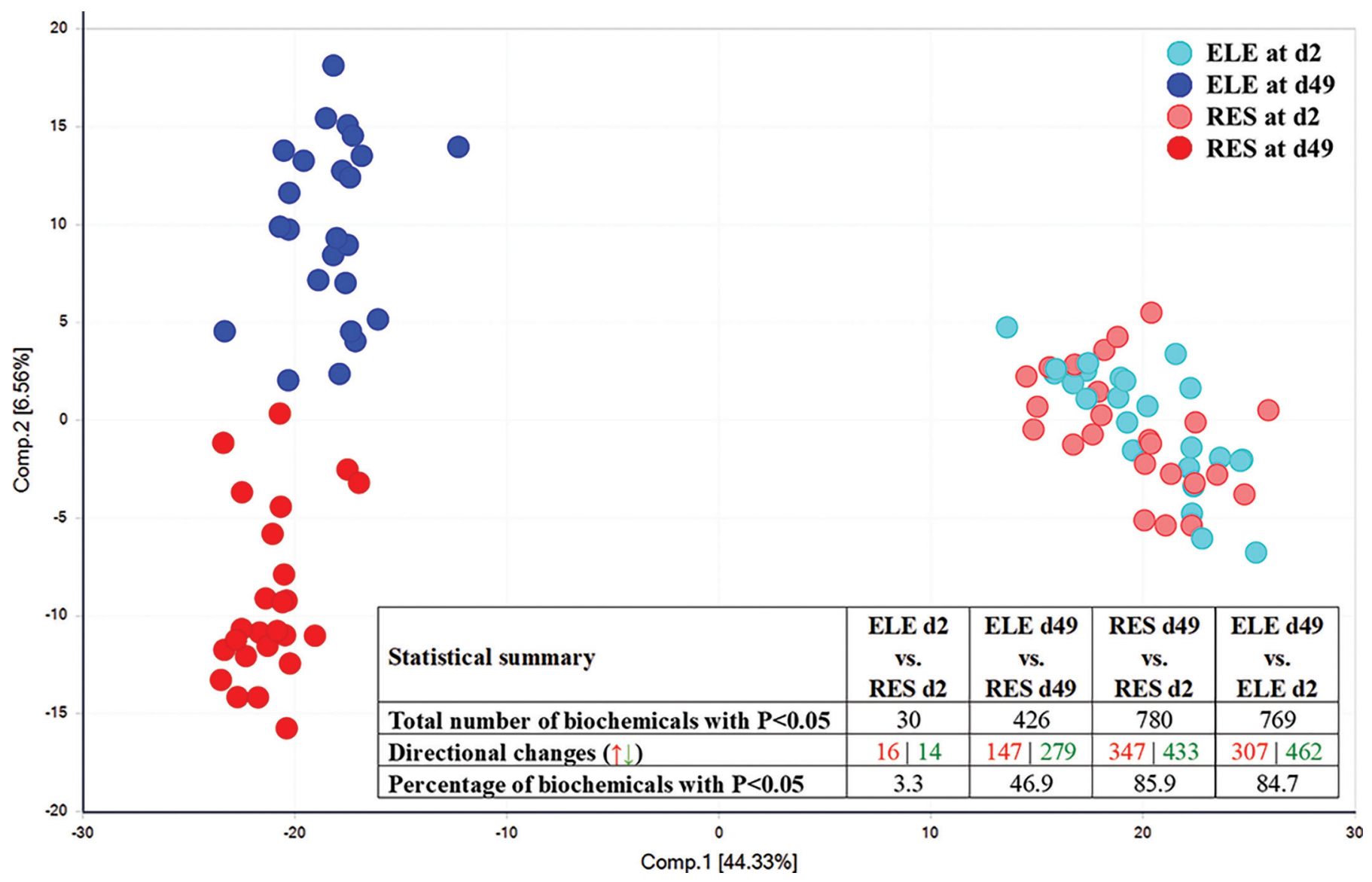

Figure 3. Principal component analysis (PCA) and statistical summary of blood metabolites of dairy calves $(\mathrm{n}=50)$ at d 2 and 49 fed a restrictive (RES) or elevated (ELE) level of nutrient intake. Each dot in the PCA represents 1 sample. 


\begin{tabular}{|c|c|c|c|c|c|}
\hline & Biochemical & $\begin{array}{c}\text { ELE d2 } \\
v s \\
\text { RES d2 }\end{array}$ & $\begin{array}{c}\text { ELE d49 } \\
\text { vs. } \\
\text { RES d49 }\end{array}$ & $\begin{array}{c}\text { RES d49 } \\
\text { vs } \\
\text { RES d2 }\end{array}$ & $\begin{array}{l}\text { ELE d49 } \\
\text { vs } \\
\text { ELE d2 }\end{array}$ \\
\hline \multirow{24}{*}{ 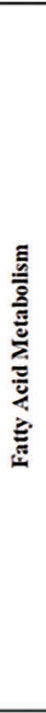 } & \begin{tabular}{|l|} 
butyrylcarnitine \\
\end{tabular} & 1.14 & 0.89 & 0.84 & 0.65 \\
\hline & butyrylglycine & 1.08 & 0.42 & 3.04 & 1.18 \\
\hline & propionylcarnitine & 1.06 & 0.57 & 1.74 & 0.93 \\
\hline & propionylglycine & 1.02 & 0.24 & 38.79 & 9.01 \\
\hline & valerylglycine & 0.97 & 0.14 & 27.85 & 4.05 \\
\hline & hexanoylglycine & 0.97 & 0.70 & 1.11 & 0.79 \\
\hline & $\mathrm{N}$-palmitoylglycine & 1.06 & 1.10 & 0.64 & 0.66 \\
\hline & \begin{tabular}{|l|} 
acetylcamitine \\
\end{tabular} & 1.10 & 1.28 & 0.56 & 0.65 \\
\hline & 3-hydroxybutyrylcarnitine & 1.14 & 1.16 & 0.27 & 0.28 \\
\hline & \begin{tabular}{|l|} 
hexanoylcarnitine \\
\end{tabular} & 1.13 & 1.22 & 0.44 & 0.47 \\
\hline & \begin{tabular}{|l|} 
octanoylcarnitine \\
\end{tabular} & 1.05 & 1.41 & 0.40 & 0.54 \\
\hline & \begin{tabular}{|l|} 
decanoylcarnitine \\
\end{tabular} & 1.06 & 1.49 & 0.17 & 0.24 \\
\hline & \begin{tabular}{|l|} 
laurylcarnitine \\
\end{tabular} & 1.01 & 1.37 & 0.29 & 0.40 \\
\hline & myristoylcarnitine & 1.06 & 1.25 & 0.37 & 0.43 \\
\hline & palmitoylcarnitine & 1.07 & 1.61 & 0.44 & 0.65 \\
\hline & palmitoleoylcamitine & 1.05 & 1.24 & 0.22 & 0.25 \\
\hline & stearoylcamitine & 1.08 & 1.23 & 0.89 & 1.01 \\
\hline & \begin{tabular}{|l|} 
linoleoylcamitine \\
\end{tabular} & 0.90 & 1.29 & 3.79 & 5.44 \\
\hline & \begin{tabular}{|l|} 
oleoylcarnitine \\
\end{tabular} & 1.05 & 1.26 & 0.44 & 0.53 \\
\hline & \begin{tabular}{|l|} 
myristoleoylcarnitine \\
\end{tabular} & 1.14 & 1.52 & 0.19 & 0.25 \\
\hline & suberoylcamitine & 0.83 & 0.94 & 0.06 & 0.07 \\
\hline & \begin{tabular}{|l|} 
adipoylcamitine \\
\end{tabular} & 0.89 & 1.18 & 0.11 & 0.14 \\
\hline & carnitine & 1.04 & 1.20 & 0.98 & 1.13 \\
\hline & 3-hydroxybutyrate (BHBA) & 1.09 & 0.39 & 2.99 & 1.08 \\
\hline \multirow{10}{*}{ 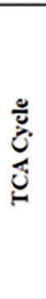 } & citrate & 0.95 & 0.80 & 1.12 & 0.95 \\
\hline & \begin{tabular}{|l} 
aconitate [cis or trans] \\
\end{tabular} & 0.92 & 0.86 & 1.04 & 0.97 \\
\hline & \begin{tabular}{|l|} 
isocitrate \\
\end{tabular} & 0.98 & 0.91 & 0.79 & 0.74 \\
\hline & alpha-ketoglutarate & 1.08 & 0.91 & 1.21 & 1.02 \\
\hline & \begin{tabular}{|l|} 
succinylcarnitine \\
\end{tabular} & 0.98 & 1.27 & 0.28 & 0.37 \\
\hline & \begin{tabular}{|l|} 
succinate \\
\end{tabular} & 1.08 & 0.85 & 1.13 & 0.89 \\
\hline & fumarate & 1.09 & 0.83 & 0.70 & 0.54 \\
\hline & \begin{tabular}{|l|} 
malate \\
\end{tabular} & 1.11 & 0.79 & 0.86 & 0.61 \\
\hline & tricarballylate & 0.83 & 0.12 & 333.09 & 48.95 \\
\hline & 2-methylcitrate/homocitrate & 0.94 & 0.62 & 1.03 & 0.68 \\
\hline
\end{tabular}



Figure 4. Heat map of long-chain fatty acids, PUFA, fatty acid metabolism, and schematics of tricarboxylic acid cycle (TCA) and associated metabolites of dairy calves $(\mathrm{n}=50)$ at $\mathrm{d} 2$ and 49 fed a restrictive $(\mathrm{RES})$ or elevated (ELE) level of nutrient intake. Red $(P<0.05)$ and green $(P$ $<0.05)$ boxes in the heat map and arrows in the schematic represent significantly increased and decreased biochemicals, respectively. Numbers in yellow in the heat map indicate the fold difference between treatments. $\mathrm{PDH}=$ pyruvate dehydrogenase protein.

groups are on the same side of the double bond; 1.49 fold, E,E (E indicates the higher priority groups are on opposite sides of the double bond)], and biliverdin (1.99-fold) in circulation.

\section{DISCUSSION}

This experiment was designed to describe the growth and metabolic differences in calves fed widely different amounts of MR preweaning. We added metabolic profiling to an experiment contrasting preweaning levels of nutrient intake to generate hypotheses of mode of action in the increasing number of publications displaying later-life effects of calf nutrition.

The ELE group received greater amounts of MR and subsequently grew faster and were heavier at weaning, similar to earlier reports on enhanced milk feeding schemes in calves (Khan et al., 2007b; Yunta et al., 2015). Average daily gain in the ELE group was greater in the first weeks of life, corresponding with their higher nutrient supply. As starter intake increased earlier and at a greater pace in the RES group, their ADG improved until treatment differences faded at wk 6 , which can be partially explained by differences in gut 


\begin{tabular}{|c|c|c|c|c|c|}
\hline & Biochemical & $\begin{array}{c}\text { ELE d2 } \\
\text { vs. } \\
\text { RES d2 } \\
\end{array}$ & $\begin{array}{c}\text { ELE d49 } \\
\text { vs. } \\
\text { RES d49 }\end{array}$ & $\begin{array}{c}\text { RES d49 } \\
\text { vs. } \\
\text { RES d2 } \\
\end{array}$ & $\begin{array}{c}\text { ELE d49 } \\
\text { vs. } \\
\text { ELE d2 } \\
\end{array}$ \\
\hline \multirow{20}{*}{ 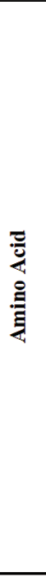 } & glycine & 1.11 & 1.01 & 1.05 & 0.96 \\
\hline & serine & 1.02 & 1.18 & 0.68 & 0.80 \\
\hline & threonine & 0.97 & 1.31 & 0.70 & 0.94 \\
\hline & alanine & 1.07 & 1.12 & 0.47 & 0.49 \\
\hline & aspartate & 1.11 & 1.15 & 1.01 & 1.04 \\
\hline & asparagine & 1.00 & 1.11 & 0.62 & 0.69 \\
\hline & glutamate & 1.01 & 1.19 & 0.54 & 0.63 \\
\hline & glutamine & 1.06 & 1.20 & 0.60 & 0.68 \\
\hline & histidine & 1.03 & 1.05 & 0.48 & 0.49 \\
\hline & lysine & 1.01 & 1.41 & 0.93 & 1.30 \\
\hline & phenylalanine & 1.04 & 1.06 & 0.96 & 0.98 \\
\hline & tyrosine & 1.10 & 1.19 & 0.64 & 0.68 \\
\hline & tryptophan & 0.98 & 1.21 & 0.60 & 0.74 \\
\hline & leucine & 1.01 & 1.05 & 0.79 & 0.82 \\
\hline & isoleucine & 0.99 & 0.98 & 1.09 & 1.08 \\
\hline & valine & 0.98 & 0.99 & 0.68 & 0.68 \\
\hline & methionine & 1.03 & 1.46 & 0.50 & 0.70 \\
\hline & cysteine & 1.02 & 1.30 & 0.52 & 0.66 \\
\hline & proline & 1.00 & 1.16 & 0.37 & 0.43 \\
\hline & arginine & 1.01 & 1.18 & 1.14 & 1.33 \\
\hline \multirow{5}{*}{ 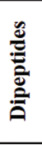 } & glycylvaline & 1.08 & 1.29 & 0.22 & 0.27 \\
\hline & isoleucylglycine & 1.09 & 1.35 & 1.17 & 1.45 \\
\hline & phenylalanylalanine & 0.89 & 1.39 & 6.72 & 10.45 \\
\hline & valylglutamine & 0.80 & 1.57 & 0.56 & 1.09 \\
\hline & valylglycine & 1.02 & 1.92 & 1.98 & 3.73 \\
\hline
\end{tabular}
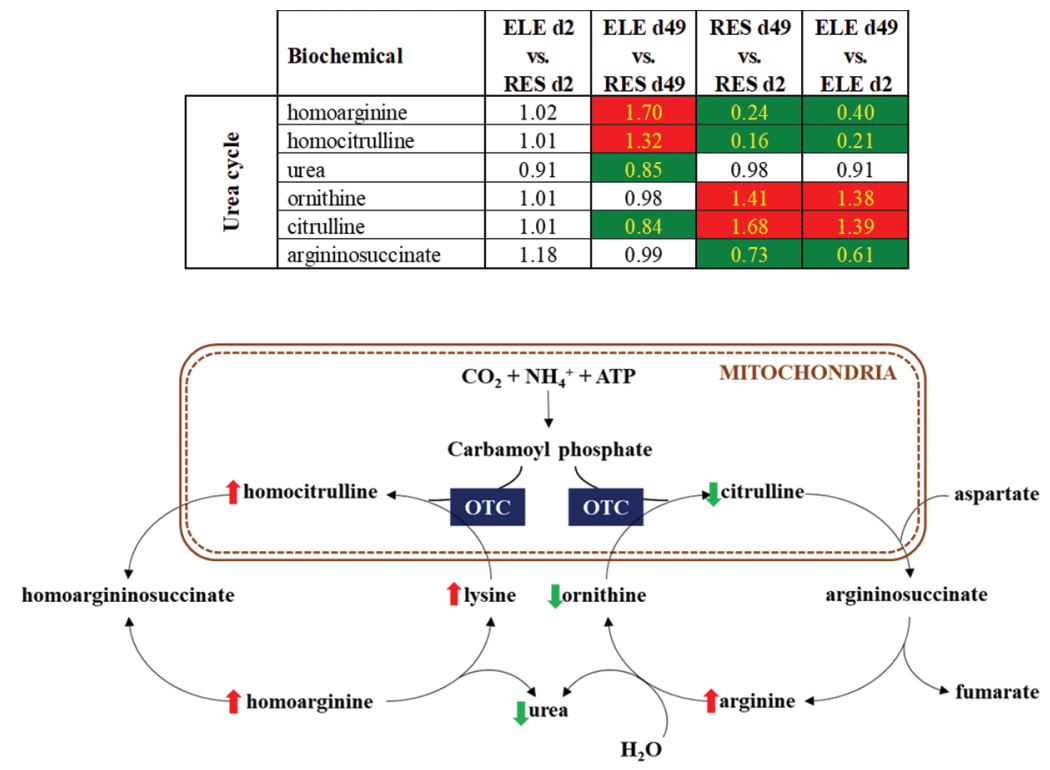

Figure 5. Heat map and schematic of dipeptides, free AA, and urea cycle and associated metabolites of dairy calves $(\mathrm{n}=50)$ at $\mathrm{d} 2$ and 49 fed a restrictive (RES) or elevated (ELE) level of nutrient intake. Red $(P<0.05)$ and green $(P<0.05)$ boxes in the heat map and arrows in the schematic represent significantly increased and decreased biochemicals, respectively. Numbers in yellow in the heat map indicate the fold difference between treatments. OTC $=$ ornithine transcarbamylase.

fill (Khan et al., 2016). The higher starter consumption in the RES group at wk 7 (53\% of the total ME intake compared with $10 \%$ in the ELE group) combined with their lower milk allowance resulted in differences in physical form of the feed consumed, with nutrient profiles and different means of digestion (ruminal vs. intestinal). These considerations suggest that the similar growth observed on wk 7 was achieved from very distinct absorbed nutrient profiles, something illustrated by metabolome analysis.

Calves were weaned on a step-down protocol (Khan et al., 2007b), which still resulted in a transient but significant reduction in ADG. A decrease in growth rate was more severe in the ELE group because starter consumption at weaning was lower. The physical capacity for additional feed intake is limited in calves consuming large quantities of milk preweaning (Jasper and Weary, 2002; Khan et al., 2007a; Davis Rincker et al., 2011), and as such, the reticulorumen requires extensive morphological and physiological adjustments before a calf is able to utilize nutrients from other nonmilk feedstuffs (Chapman et al., 2016; Khan et al., 2016). The decrease in growth rate at weaning in the ELE group reflects the time required both for starter intake to increase and for the gastrointestinal tract (especially the reticulorumen) to develop the ability to digest solid feeds and assimilate nutrients for growth (Hill et al., 2016; Meale et al., 2017a).
Because MR comprised such a large component of total ME and CP intake, the first weaning step resulted in decreases of 39 and $36 \%$, respectively, for the ELE group and 20 and $17 \%$, respectively, for the RES group. Similarly, the second and final weaning step decreased ME and CP intakes by 38 and $42 \%$, respectively, for the ELE group and 18 and $12 \%$, respectively, for the RES group. The smaller decrease in CP intake (Supplemental Figure S2A, http://dx.doi.org/10.17632/9z95ygk3s2.1; Leal, 2021b) in the RES group at the final weaning step indicates that the calves had become less reliant on MR intake, which is also clear from the higher starter and consistent DMI increase for the duration of the study. Postweaning (wk 9) DMI, ADG, and feed efficiency lagged behind in the ELE group compared with the RES group. Similarly, as reported by Steele et al. (2017), DMI for calves in the ELE treatment declined because the withdrawal of MR was not compensated by an immediate increase in starter. Under natural circumstances, calves transition from milk to solid feed over several weeks, in a process that occurs at approximately 10 mo of age (Reinhardt and Reinhardt, 1981). This contrasts with what occurs in commercial dairy production systems, were calves are weaned between 6 and 8 wk of age (USDA, 2011). In addition to weaning later in life, the step-down weaning protocol has been shown to be more suitable for calves weaned at $56 \mathrm{~d}$ of age (Eckert et al., 2015) and offered an elevated level 
of nutrient intake (Steele et al., 2017), but present data suggest further improvements are necessary to facilitate a smoother transition to solid feed.

Principal component analysis revealed large metabolic shifts between the groups from birth to d 49. This is not surprising given the natural physiological adaptations (from nonruminants to preruminants) and the dietary changes (from colostrum to milk and starter) these animals experienced during this period. Calves assigned to the groups shared a common metabolic profile at the start but had clearly distinct metabolic profiles at d 49 as a result of the widely different dietary treatments. Although information on the effects of early-life nutrition on adaptations of the metabolome is scarce in the literature, distinct differences between ad libitum-reared and restrictively reared calves both during calfhood and during first lactation have recently been documented (Kenéz et al., 2018). Similarly, diurnal metabolic patterns in calves fed an elevated level of nutrient intake have also recently been described (Ghaffari et al., 2017), demonstrating the value of this approach to describe effects in response to nutrient intake in young calves.

From birth to just before the onset of weaning, the physiology of a calf changes dramatically, transitioning from a nonruminant to a preruminant (Drackley, 2008). The calf relies on glucogenic nutrients directly from milk or MR to meet requirements for growth and development during the nonruminant phase. During this time, feed efficiency is at the highest point in the development process. Consumption of large amounts of starter in early life has proven to anticipate rumen development (Baldwin et al., 2004) but at an inherent loss of efficiency. Rumen microbes convert dietary nutrients, resulting in a larger fraction of ketogenic nutrients, which typically results in lower growth rates.

Our metabolomics data revealed lower levels of BHB and the butyrate and propionate surrogates butyrylglycine, propionylcarnitine, and propionylglycine at d 49 in the ELE group, which reflects the lower starter intake on this treatment. The difference in these volatile fatty acids in the RES group from d 2 to 49 is a clear

\begin{tabular}{|c|c|c|c|c|c|}
\hline & Biochemical & $\begin{array}{c}\text { ELE d2 } \\
\text { vs. } \\
\text { RES d2 }\end{array}$ & $\begin{array}{c}\text { ELE d49 } \\
\text { vs. } \\
\text { RES d49 }\end{array}$ & $\begin{array}{c}\text { RES d49 } \\
\text { vs. } \\
\text { RES d2 }\end{array}$ & $\begin{array}{c}\text { ELE d49 } \\
\text { vs. } \\
\text { ELE d2 }\end{array}$ \\
\hline \multirow{9}{*}{ 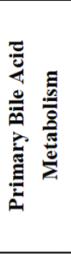 } & cholate & 1.08 & 0.02 & 155.61 & 2.88 \\
\hline & glycocholate & 1.01 & 0.26 & 2.19 & 0.57 \\
\hline & taurocholate & 1.09 & 1.22 & 1.37 & 1.53 \\
\hline & chenodeoxycholate & 1.15 & 0.08 & 28.49 & 1.99 \\
\hline & glycochenodeoxycholate & 1.06 & 2.17 & 0.80 & 1.62 \\
\hline & taurochenodeoxycholate & 1.13 & 6.42 & 0.25 & 1.41 \\
\hline & tauro-alpha-muricholate & 0.93 & 4.16 & 1.21 & 5.41 \\
\hline & tauro-beta-muricholate & 0.95 & 1.60 & 5.37 & 9.06 \\
\hline & glycochenodeoxycholate sulfate & 0.84 & 0.83 & 1.79 & 1.78 \\
\hline \multirow{16}{*}{ 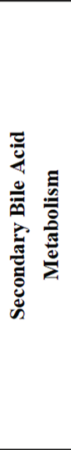 } & deoxycholate & 1.42 & 0.02 & 530.53 & 8.10 \\
\hline & glycodeoxycholate & 1.01 & 0.38 & 22.64 & 8.59 \\
\hline & taurodeoxycholate & 1.26 & 1.13 & 9.85 & 8.78 \\
\hline & lithocholate & 0.97 & 0.23 & 4.91 & 1.16 \\
\hline & glycolithocholate & 0.97 & 0.45 & 128.36 & 59.92 \\
\hline & glycolithocholate sulfate & 0.99 & 0.27 & 10.17 & 2.73 \\
\hline & taurolithocholate & 1.08 & 2.45 & 17.57 & 39.88 \\
\hline & taurolithocholate 3-sulfate & 0.95 & 1.50 & 2.94 & 4.64 \\
\hline & ursodeoxycholate & 0.91 & 2.01 & 7.42 & 16.34 \\
\hline & glycoursodeoxycholate & 0.84 & 31.57 & 1.34 & 50.62 \\
\hline & tauroursodeoxycholate & 0.98 & 52.57 & 0.92 & 49.55 \\
\hline & glycohyodeoxycholate & 1.13 & 1.26 & 0.08 & 0.09 \\
\hline & 3-dehydrocholate & 0.93 & 0.30 & 2.03 & 0.66 \\
\hline & taurocholenate sulfate & 1.29 & 2.15 & 0.44 & 0.73 \\
\hline & 7-ketodeoxycholate & 0.98 & 0.26 & 1.15 & 0.30 \\
\hline & 3beta,7alpha-dihydroxy-5-cholestenoate & 0.77 & 1.59 & 0.06 & 0.12 \\
\hline \multirow{5}{*}{ 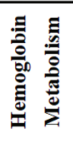 } & heme & 1.15 & 1.55 & 1.46 & 1.96 \\
\hline & bilirubin $(\mathrm{Z}, \mathrm{Z})$ & 1.13 & 1.22 & 0.19 & 0.20 \\
\hline & bilirubin $(\mathrm{E}, \mathrm{E})$ & 1.10 & 1.49 & 0.09 & 0.12 \\
\hline & bilirubin $(E, Z$ or $Z, E)$ & 1.12 & 1.06 & 0.27 & 0.26 \\
\hline & biliverdin & 1.24 & 1.99 & 0.07 & 0.12 \\
\hline
\end{tabular}

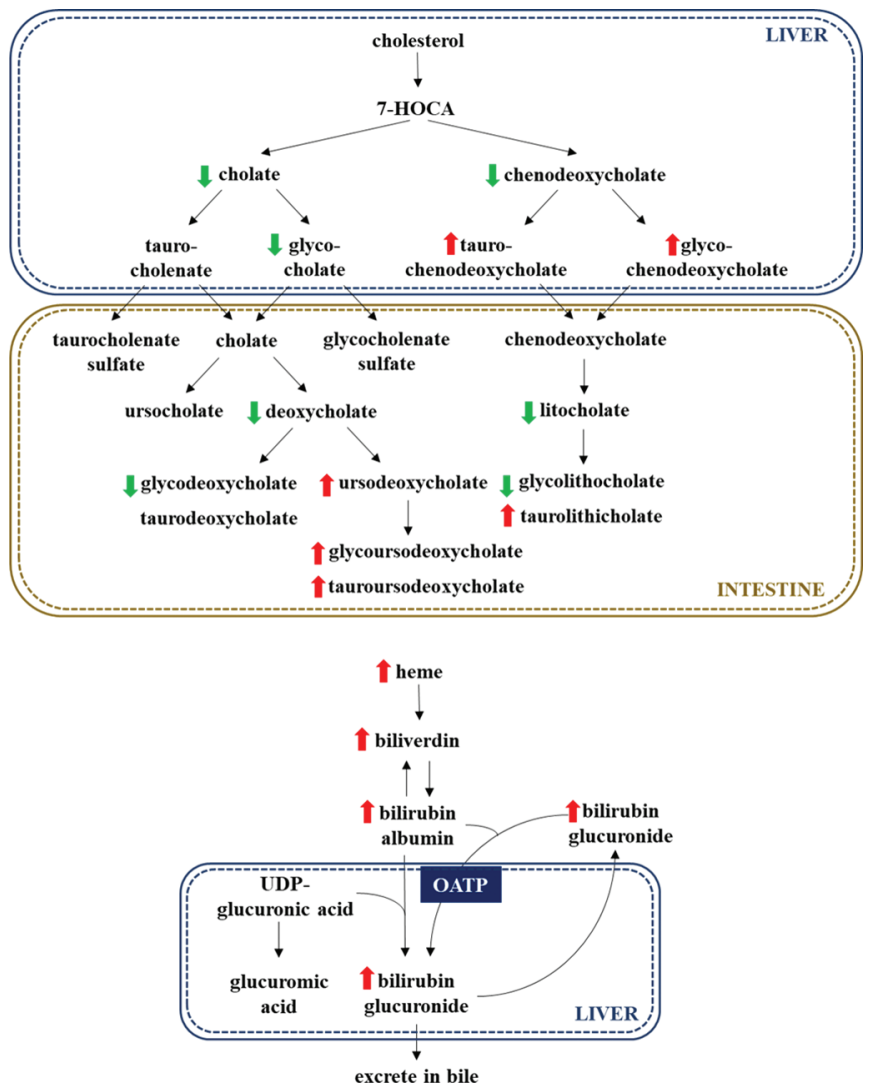

Figure 6. Heat map and schematic of bile acid and hemoglobin metabolism and associated metabolites of dairy calves (n $=50)$ at $\mathrm{d} 2$ and 49 fed a restrictive (RES) or elevated (ELE) level of nutrient intake. Red $(P<0.05)$ and green $(P<0.05)$ boxes in the heat map and arrows in the schematic represent significantly increased and decreased biochemicals, respectively. Numbers in yellow in the heat map indicate the fold difference between treatments. OATP = organic-anion-transporting polypeptides; 7-HOCA = 7alpha-hydroxy-3-oxo-4-cholestenoic acid; UDP $=$ uridine diphosphate; $\mathrm{E}$ indicates the higher priority groups are on opposite sides of the double bond; Z indicates the higher priority groups are on the same side of the double bond. 
response to its greater starter intake during this time. The greater starter consumption in the RES group to wk 7 means that these calves assimilated a different nutrient profile compared with their ELE counterparts. It is reasonable to suggest that calves in the ELE group presented a quantitatively and qualitatively different ruminal microbial population and a less developed rumen at the start of weaning, which is described in the literature (Yáñez-Ruiz et al., 2015). This is supported by the observed decreased levels of BHB, which is an indicator of metabolic function of the rumen epithelium (Pennington, 1952). Additionally, glycolytic metabolites such as pyruvate, lactate, fumarate, and malate showed consistent decreases in both groups from birth to weaning. Furthermore, rumen function development is evident by the observed increase in VFA from microbial fermentation of carbohydrates as starter intake increased in both groups. These microbial-derived metabolites were lower in the ELE group on d 49, illustrating a different microbial digestion at weaning resulting from different milk supply preweaning. Despite the scarce description of this process in the literature, recent evidence suggests that age at weaning strongly influences the microbiome of young calves (Meale et al., 2017b).

Several LCFA and PUFA decreased, whereas a selection of PUFA showed increases from birth to weaning independently from treatment. Those differences in circulating fatty acids reflect changes in dietary lipid composition as the ratio of solid feed to MR intake increased. In both groups, the metabolic fatty acid profile at d 49 contained higher levels of PUFA such as linoleate, arachidonate, adrenate, and docosapentaenoate while containing lower levels of other fatty acids compared with d 2. Notably, the calves receiving the ELE diet had lower levels of several circulating LCFA and PUFA. As odd-chain fatty acids are derived from microbial metabolism of dietary lipid in the gut (Weitkunat et al., 2017), the lower concentration of odd-chain LCFA in the ELE group could reflect differences in ruminal activity between the treatments at d 49. Noteworthy, in both groups, fatty acid metabolism at d 49 was characterized by an increase in propionylcarnitine and propionylglycine and a reduction in acylcarnitines compared with d 2. However, circulating acylcarnitines were increased in the ELE group at d 49. Acylcarnitines are involved in mitochondrial transport of fatty acids; therefore, an increase in acylcarnitines in ELE calves may indicate a link between milk replacer supply and mitochondrial function (Kenéz et al., 2018).

Higher preweaning milk supply resulted in higher levels of numerous dipeptides and AA in plasma. This response can largely be attributed to $\mathrm{CP}$ intake, which was $7 \%$ higher at d 49 in the ELE group, and to the greater digestibility of milk proteins compared with vegetable proteins in the calf starter (Raeth et al., 2016). Although most EAA were elevated in the ELE group, the branched-chain AA were not different at d 49. Methionine and lysine are generally accepted to be, respectively, first and second limiting for milk protein synthesis (Schwab et al., 1976), but the branched-chain AA are largely regarded to have the strongest influence on skeletal muscle synthesis in the growing neonate (Suryawan et al., 2012; Manjarín et al., 2016). Capacity for high rates of growth and protein synthesis is greatest in the young mammalian neonate (Denne and Kalhan, 1987; Davids et al., 2012) and can be maximized with increased nutrient intake (Preedy and Garlick, 1986). Relative to the other EAA, lower circulating concentrations of branched-chain AA may therefore reflect increased uptake to support growth in the ELE group.

Higher levels of methionine in the ELE group just before weaning not only made more protein available for the calves but also may have activated selective pathways. Increased levels of cystathionine and cysteine in the ELE group on d 49 suggest that the increased methionine may enhance the supply of other sulfur-containing AA to these animals. Cystathionine and cysteine also serve as the precursors of glutathione and taurine, perhaps enhancing antioxidative and osmoprotective capacity (Selhub, 1999). Methionineassociated metabolites such as choline and betaine were also elevated in the ELE group at d 49, which may have implications on hepatic fatty acid metabolism (Zeisel and da Costa, 2009) and muscle growth (Waldroup and Fritts, 2005). Elevated concentrations of arginine and lysine in the ELE treatment have been linked to urea metabolism through the activity of the enzyme ornithine transcarbamylase (OTC). Homocitrulline (HCit), a nonproteinogenic AA that is synthesized by OTC from the condensation of carbamoyl-phosphate and lysine, is subsequently converted to homoarginine (Davids et al., 2012). In humans, the formation of HCit is secondary to the main role of OTC in condensing carbamoyl-phosphate and ornithine in the urea cycle. Thus, HCit and homoarginine usually arise when there is depletion of ornithine supply, which is indicative of urea cycle disorders, causing an accumulation of carbamoyl-phosphate that is shunted toward HCit production. It has been shown that HCit is positively correlated with urea concentrations during renal failure (Desmons et al., 2017), though in this study HCit was negatively correlated with urea concentrations. Furthermore, we did not observe any adverse health in the ELE group, suggesting that elevated HCit is not necessarily indicative of a particular disorder.

Hepatic changes observed between treatments centered largely on bile acid and heme metabolism. Numer- 
ous primary and secondary bile acids showed elevations from d 2 to 49 for both treatments, reflecting both the maturation of the liver and the need to emulsify dietary fat, which dietary supply increased 176 and $70 \%$ in the ELE and RES groups, respectively (Supplemental Figure S2B, http://dx.doi.org/10.17632/9z95ygk3s2.1; Leal, 2021b). The ELE treatment had $>90 \%$ decreases in primary bile acids such as cholate and chenodeoxycholate and $>75 \%$ decreases in secondary bile acids such as deoxycholate and lithocholate at $d$ 49. The preruminant hydrolyzes lipid in the abomasum and duodenum through the activity of pregastric esterase (Grosskopf, 1965).

The primary bile acids are conjugated with either taurine or glycine to form bile salts that are subsequently secreted into bile (Martin et al., 2007; Qi et al., 2015), which then emulsify dietary triglyceride for conversion into free fatty acid by pancreatic lipase. With the exception of chenodeoxycholate, decreases in these primary bile acids cannot easily be explained by their increased glycine and taurine conjugates. These phenomena could be a consequence of reduced bile acid production, enhanced hepatic bile acid reabsorption, or enhanced fecal bile acid excretion in the ELE treatment group. Metabolomics analyses of liver and feces are required to understand the underlying cause of such signatures. As bile is the major excretory route for endogenous compounds such as bilirubin, increased levels for the ELE group suggest a reduction in bile acid production (Engelking, 1993; Boyer, 2013). These results are surprising, as at $d 49$ the ELE group consumed significantly more fat per day. On the other hand, the discrepancy between lipid intake and bile acid production in the ELE group could also be attributed to a competition for carriers in events of hyperlipidemia, which can affect bilirubin uptake into bile acids, something that would not necessarily mean a reduction in total bile acid production (Engelking, 1993). Cholate is the predominant bile acid in the mature ruminant (Sheriha et al., 1968), so the large increase in concentration in the RES treatment may be the response to the higher solid feed and lower lipid intake, indicating greater gastrointestinal tract development in this group. This notion is also supported by the elevated concentration of the microbially derived secondary bile acids deoxycholate and glycolithocholate, perhaps reflecting differential microbial population or genera in the gut (Brandl et al., 2017). From d 2 to 49, all animals had increased circulating heme and decreased heme breakdown products such as bilirubin and biliverdin. Because of the high MR intake, iron consumption in the ELE group was $38 \%$ higher at d 49, suggesting that a strong anabolic signal was responsible for the greater circulating heme to support growth (Underwood, 1977). The increased circulating heme may be associated with an increasing need of red blood cells to supply sufficient oxygen for growth and for the formation of myoglobin in muscle (Khan and Quigley, 2011). The change in nutrient profile of absorbed nutrients in the transition from nonruminant to ruminant is a shift from a glucogenic to a ketogenic diet. As such, the animal is required to increase oxidative capacity, as VFA and ketone bodies are extensively taken up and catabolized in muscle tissue of mature ruminants (van Houtert, 1993). The decreased circulating bilirubin and biliverdin in the RES calves may be explained by higher heme concentrations and more efficient elimination of these wastes via enhanced hepatic bile acid secretion. Calves receiving the ELE diet had higher levels of heme as well as the breakdown products. These signatures could suggest that the ELE group may require higher red blood cell production to support its rapid growth, resulting in higher levels of heme and heme breakdown products. However, accumulation of biliverdin and bilirubin in the ELE group suggests that heme was not incorporated into any functional protein complex and can be associated with reduced bile acid production, leading to reduced clearance of these wastes.

Metabolomics profiling in conjunction with intake and growth data helped us shed light on the metabolic pathways primed by preweaning nutrition that may explain future productive outcomes in dairy cows. It is important to note that discussed differences between calves fed RES and ELE are limited to the first $49 \mathrm{~d}$ of life. Following the withdrawal of the treatments and as the heifers develop toward lactation, it is expected that differences in metabolomics will be reduced. Therefore, further research is warranted to explore the carryover effects of preweaning nutrition on the metabolic profile of developing heifers.

\section{CONCLUSIONS}

In the present study, we demonstrated differences in growth and development in young calves fed elevated or restricted levels of nutrient intake during the preweaning period. Phenotypic differences were supported with characteristic metabolic profiles associated with differential growth between the treatment groups. Clear responses in energy and protein metabolism reflect greater nutrient intake and partitioning toward growth in the ELE group, which was further supported by differences in microbial-derived metabolites and hepatic metabolic profiles. Further research is warranted to describe the effect of nutritional programming during the preruminant phase on metabolic and production parameters in later life of dairy Holstein calves. 


\section{ACKNOWLEDGMENTS}

The authors thank Mieke Langen-Thijssen, Filipe Lino, Samuel Benítez, Sonia López, and the staff of the Dairy Research Facility of Trouw Nutrition (Boxmeer, the Netherlands) for their skilled technical assistance. The present study was funded by, and several of the authors are employed by, Trouw Nutrition (Amersfoort, the Netherlands), a company with commercial interests in calf nutrition.

\section{REFERENCES}

Baldwin, R. L. V., K. R. McLeod, J. L. Klotz, and R. N. Heitmann. 2004. Rumen development, intestinal growth and hepatic metabolism in the pre- and postweaning ruminant. J. Dairy Sci. 87:E55E65. https://doi.org/10.3168/jds.S0022-0302(04)70061-2.

Bar-Peled, U., B. Robinzon, E. Maltz, H. Tagari, Y. Folman, I. Bruckental, H. Voet, H. Gacitua, and A. R. Lehrer. 1997. Increased weight gain and effects on production parameters of Holstein heifer calves that were allowed to suckle from birth to six weeks of age. J. Dairy Sci. 80:2523-2528. https://doi.org/10.3168/jds.S0022 -0302(97)76205-2.

Berry, M. J., A. L. Jaquiery, M. H. Oliver, J. E. Harding, and F. H. Bloomfield. 2016. Neonatal milk supplementation in lambs has persistent effects on growth and metabolic function that differ by sex and gestational age. Br. J. Nutr. 116:1912-1925. https://doi .org/10.1017/S0007114516004013.

Boubred, F., A. Jamin, C. Buffat, L. Daniel, P. Borel, G. Boudry, I. Le Hueron-Luron, and U. Simeoni. 2017. Neonatal high protein intake enhances neonatal growth without significant adverse renal effects in spontaneous IUGR piglets. Physiol. Rep. 5:e13296. https://doi .org/10.14814/phy2.13296.

Boyer, J. L. 2013. Bile formation and secretion. Compr. Physiol. 3:1035-1078. https://doi.org/10.1002/cphy.c120027.

Brandl, K., V. Kumar, and L. Eckmann. 2017. Gut-liver axis at the frontier of host-microbial interactions. Am. J. Physiol. Gastrointest. Liver Physiol. 312:G413-G419. https://doi.org/10.1152/ajpgi .00361 .2016 .

Chapman, C. E., P. S. Erickson, J. D. Quigley, T. M. Hill, H. G. Bateman II, F. X. Suarez-Mena, and R. L. Schlotterbeck. 2016. Effect of milk replacer program on calf performance and digestion of nutrients with age of the dairy calf. J. Dairy Sci. 99:2740-2747. https://doi.org/10.3168/jds.2015-10372.

Davids, M., J. D. Ndika, G. S. Salomons, H. J. Blom, and T. Teerlink. 2012. Promiscuous activity of arginine:glycine amidinotransferase is responsible for the synthesis of the novel cardiovascular risk factor homoarginine. FEBS Lett. 586:3653-3657. https://doi.org/10 .1016/j.febslet.2012.08.020.

Davis Rincker, L. E., M. J. VandeHaar, C. A. Wolf, J. S. Liesman, L. T. Chapin, and M. S. Weber Nielsen. 2011. Effect of intensified feeding of heifer calves on growth, pubertal age, calving age, milk yield, and economics. J. Dairy Sci. 94:3554-3567. https://doi.org/ 10.3168/jds.2010-3923.

Delamaire, E., P. Parnet, B. Coupe, C. Hoebler, S. Blat, G. Poupeau, C. Y. Boquien, M. Champ, and D. Darmaun. 2012. Long term metabolic impact of high protein neonatal feeding: A preliminary study in male rat pups born with a low birth weight. Clin. Nutr. 31:741-748. https://doi.org/10.1016/j.clnu.2012.02.005.

Denne, S. C., and S. C. Kalhan. 1987. Leucine metabolism in human newborns. Am. J. Physiol. 253:E608-E615. https://doi.org/ 10.1152/ajpendo.1987.253.6.E608.

Desmons, A., S. Jaisson, N. Leroy, P. Gillery, and E. Guillard. 2017. Labile glycated haemoglobin and carbamylated haemoglobin are still critical points for $\mathrm{HbA}(1 \mathrm{c})$ measurement. Biochem. Med. (Zagreb) 27:378-386. https://doi.org/10.11613/BM.2017.039.

Diaz, M. C., M. E. Van Amburgh, J. M. Smith, J. M. Kelsey, and E. L. Hutten. 2001. Composition of growth of Holstein calves fed milk replacer from birth to 105-kilogram body weight. J. Dairy Sci. 84:830-842. https://doi.org/10.3168/jds.S0022-0302(01)74541-9.

Drackley, J. K. 2008. Calf nutrition from birth to breeding. Vet. Clin. North Am. Food Anim. Pract. 24:55-86. https://doi.org/10.1016/ j.cvfa.2008.01.001.

Eckert, E., H. E. Brown, K. E. Leslie, T. J. DeVries, and M. A. Steele. 2015. Weaning age affects growth, feed intake, gastrointestinal development, and behavior in Holstein calves fed an elevated plane of nutrition during the preweaning stage. J. Dairy Sci. 98:6315-6326. https://doi.org/10.3168/jds.2014-9062.

Engelking, L. R. 1993. Equine fasting hyperbilirubinemia. Adv. Vet. Sci. Comp. Med. 37:115-125.

Eriksson, J. G., T. Forsen, J. Tuomilehto, C. Osmond, and D. J. Barker. 2003. Early adiposity rebound in childhood and risk of Type 2 diabetes in adult life. Diabetologia 46:190-194. https://doi.org/10 .1007/s00125-002-1012-5.

Evans, A. M., C. D. DeHaven, T. Barrett, M. Mitchell, and E. Milgram. 2009. Integrated, nontargeted ultrahigh performance liquid chromatography/electrospray ionization tandem mass spectrometry platform for the identification and relative quantification of the small-molecule complement of biological systems. Anal. Chem. 81:6656-6667. https://doi.org/10.1021/ac901536h.

Foldager, J., and C. C. Krohn. 1994. Heifer calves reared on very high or normal levels of whole milk from birth to 6-8 weeks of age and their subsequent milk production. Proc. Soc. Nutr. Physiol. 3:301.

Ghaffari, M. H., J. A. R. MacPherson, H. Berends, and M. A. Steele. 2017. Diurnal variation of NMR based blood metabolites in calves fed a high plane of milk replacer: A pilot study. BMC Vet. Res. 13:271. https://doi.org/10.1186/s12917-017-1185-2.

Grosskopf, J. F. 1965. Studies on salivary lipase in young ruminants. Onderstepoort J. Vet. Res. 32:153-180.

Hall, R. D. 2006. Plant metabolomics: From holistic hope, to hype, to hot topic. New Phytol. 169:453-468. https://doi.org/10.1111/j .1469-8137.2005.01632.x

Hanley, B., J. Dijane, M. Fewtrell, A. Grynberg, S. Hummel, C. Junien, B. Koletzko, S. Lewis, H. Renz, M. Symonds, M. Gros, L. Harthoorn, K. Mace, F. Samuels, and E. M. van Der Beek. 2010. Metabolic imprinting, programming and epigenetics-A review of present priorities and future opportunities. Br. J. Nutr. 104(Suppl. 1):S1-S25. https://doi.org/10.1017/S0007114510003338.

Hill, T. M., J. D. Quigley, H. G. Bateman II, F. X. Suarez-Mena, T. S. Dennis, and R. L. Schlotterbeck. 2016. Effect of milk replacer program on calf performance and digestion of nutrients in dairy calves to 4 months of age. J. Dairy Sci. 99:8103-8110. https://doi .org/10.3168/jds.2016-11239.

Jasper, J., and D. M. Weary. 2002. Effects of ad libitum milk intake on dairy calves. J. Dairy Sci. 85:3054-3058. https://doi.org/10.3168/ jds.S0022-0302(02)74391-9.

Kenéz, Á., C. Koch, M. Korst, J. Kesser, K. Eder, H. Sauerwein, and K. Huber. 2018. Different milk feeding intensities during the first 4 weeks of rearing dairy calves: Part 3: Plasma metabolomics analysis reveals long-term metabolic imprinting in Holstein heifers. J. Dairy Sci. 101:8446-8460. https://doi.org/10.3168/jds.2018-14559.

Khan, A. A., and J. G. Quigley. 2011. Control of intracellular heme levels: Heme transporters and heme oxygenases. Biochim. Biophys. Acta 1813:668-682. https://doi.org/10.1016/j.bbamcr.2011 .01 .008 .

Khan, M. A., A. Bach, D. M. Weary, and M. A. G. von Keyserlingk. 2016. Invited review: Transitioning from milk to solid feed in dairy heifers. J. Dairy Sci. 99:885-902. https://doi.org/10.3168/jds.2015 -9975 .

Khan, M. A., H. J. Lee, W. S. Lee, H. S. Kim, K. S. Ki, T. Y. Hur, G. H. Suh, S. J. Kang, and Y. J. Choi. 2007a. Structural growth, rumen development, and metabolic and immune responses of Holstein male calves fed milk through step-down and conventional methods. J. Dairy Sci. 90:3376-3387. https://doi.org/10.3168/jds .2007-0104.

Khan, M. A., H. J. Lee, W. S. Lee, H. S. Kim, S. B. Kim, K. S. Ki, J. K. Ha, H. G. Lee, and Y. J. Choi. 2007b. Pre- and postweaning performance of Holstein female calves fed milk through step-down 
and conventional methods. J. Dairy Sci. 90:876-885. https://doi .org/10.3168/jds.S0022-0302(07)71571-0.

Leal, L. 2021a. Supplementary figure S1. Metabolomics in calves. Mendeley Data, V2. http://dx.doi.org/10.17632/wb7v54r2p4.1.

Leal, L. 2021b. Supplementary figure S2. Metabolomics in calves. Mendeley Data V1. https://doi.org/10.17632/9z95ygk3s2.1.

Lucas, A. 1991. Programming by early nutrition in man. Ciba Found. Symp. 156:38-50.

Manjarín, R., D. A. Columbus, A. Suryawan, H. V. Nguyen, A. D. Hernandez-García, N.-M. Hoang, M. L. Fiorotto, and T. Davis. 2016. Leucine supplementation of a chronically restricted protein and energy diet enhances mTOR pathway activation but not muscle protein synthesis in neonatal pigs. Amino Acids 48:257-267. https://doi.org/10.1007/s00726-015-2078-y.

Martin, F. P., M. E. Dumas, Y. Wang, C. Legido-Quigley, I. K. Yap, H. Tang, S. Zirah, G. M. Murphy, O. Cloarec, J. C. Lindon, N. Sprenger, L. B. Fay, S. Kochhar, P. van Bladeren, E. Holmes, and J. K. Nicholson. 2007. A top-down systems biology view of microbiome-mammalian metabolic interactions in a mouse model. Mol. Syst. Biol. 3:112. https://doi.org/10.1038/msb4100153.

Meale, S. J., F. Chaucheyras-Durand, H. Berends, L. L. Guan, and M. A. Steele. 2017a. From pre- to postweaning: Transformation of the young calf's gastrointestinal tract. J. Dairy Sci. 100:5984-5995. https://doi.org/10.3168/jds.2016-12474.

Meale, S. J., S. C. Li, P. Azevedo, and H. Derakhshani. 2017b. Weaning age influences the severity of gastrointestinal microbiome shifts in dairy calves. Sci. Rep. 7:198. https://doi.org/10.1038/s41598 -017-00223-7.

Ness, A. R. 2004. The Avon Longitudinal Study of Parents and Children (ALSPAC) - A resource for the study of the environmental determinants of childhood obesity. Eur. J. Endocrinol. 151:U141U149. https://doi.org/10.1530/eje.0.151u141.

NRC (National Research Council). 2001. Nutrient requirements of dairy cattle. 7th rev. ed. National Academies Press.

Oliver, S. G., M. K. Winson, D. B. Kell, and F. Baganz. 1998. Systematic functional analysis of the yeast genome. Trends Biotechnol. 16:373-378. https://doi.org/10.1016/S0167-7799(98)01214-1.

Pennington, R. J. 1952. The metabolism of short-chain fatty acids in the sheep. 1. Fatty acid utilization and ketone body production by rumen epithelium and other tissues. Biochem. J. 51:251-258. https://doi.org/10.1042/bj0510251.

Preedy, V. R., and P. J. Garlick. 1986. The response of muscle protein synthesis to nutrient intake in postabsorptive rats: The role of insulin and amino acids. Biosci. Rep. 6:177-183. https://doi.org/ $10.1007 / \mathrm{BF} 01115004$

Qi, Y., C. Jiang, J. Cheng, K. W. Krausz, T. Li, J. M. Ferrell, F. J. Gonzalez, and J. Y. Chiang. 2015. Bile acid signaling in lipid metabolism: Metabolomic and lipidomic analysis of lipid and bile acid markers linked to anti-obesity and anti-diabetes in mice. Biochim. Biophys. Acta 1851:19-29. https://doi.org/10.1016/j.bbalip.2014 .04 .008 .

Radcliff, R. P., M. J. Vandehaar, L. T. Chapin, T. E. Pilbeam, D. K. Beede, E. P. Stanisiewski, and H. A. Tucker. 2000. Effects of diet and injection of bovine somatotropin on prepubertal growth and first-lactation milk yields of Holstein cows. J. Dairy Sci. 83:23-29. https://doi.org/10.3168/jds.S0022-0302(00)74850-8.

Raeth, M., H. Chester-Jones, D. Ziegler, B. Ziegler, D. Schimek, D. L. Cook, G. Golombeski, and A. V. Grove. 2016. Pre-and postweaning performance and health of dairy calves fed milk replacers with differing protein sources. Prof. Anim. Sci. 32:833-841. https://doi .org/10.15232/pas.2016-01536.

Raeth-Knight, M., H. Chester-Jones, S. Hayes, J. Linn, R. Larson, D. Ziegler, B. Ziegler, and N. Broadwater. 2009. Impact of conventional or intensive milk replacer programs on Holstein heifer performance through six months of age and during first lactation. J. Dairy Sci. 92:799-809. https://doi.org/10.3168/jds.2008-1470.
Reinhardt, V., and A. Reinhardt. 1981. Natural sucking performance and age at weaning in zebu cattle (Bos indicus). J. Agric. Sci. 96:309-312. https://doi.org/10.1017/S0021859600066089.

Schwab, C. G., L. D. Satter, and B. Clay. 1976. Response to lactating dairy cows to abomasal infusion of amino acids. J. Dairy Sci. 59:1254-1270. https://doi.org/10.3168/jds.S0022-0302(76)84354 -8 .

Selhub, J. 1999. Homocysteine metabolism. Annu. Rev. Nutr. 19:217246. https://doi.org/10.1146/annurev.nutr.19.1.217.

Sheriha, G. M., G. R. Waller, T. Chan, and A. D. Tillman. 1968. Composition of bile acids in ruminants. Lipids 3:72-78. https:// doi.org/10.1007/BF02530972.

Soberon, F., E. Raffrenato, R. W. Everett, and M. E. Van Amburgh. 2012. Preweaning milk replacer intake and effects on long-term productivity of dairy calves. J. Dairy Sci. 95:783-793. https://doi .org/10.3168/jds.2011-4391.

Steele, M. A., J. H. Doelman, L. N. Leal, F. Soberon, M. Carson, and J. A. Metcalf. 2017. Abrupt weaning reduces postweaning growth and is associated with alterations in gastrointestinal markers of development in dairy calves fed an elevated plane of nutrition during the preweaning period. J. Dairy Sci. 100:5390-5399. https:// doi.org/10.3168/jds.2016-12310.

Suryawan, A., R. M. Torrazza, M. C. Gazzaneo, R. A. Orellana, M. L. Fiorotto, S. W. El-Kadi, N. Srivastava, H. V. Nguyen, and T. A. Davis. 2012. Enteral leucine supplementation increases protein synthesis in skeletal and cardiac muscles and visceral tissues of neonatal pigs through mTORC1-dependent pathways. Pediatr. Res. 71:324-331. https://doi.org/10.1038/pr.2011.79.

Underwood, E. J. 1977. Trace Elements in Human and Animal Nutrition. 4th ed. Academic Press.

USDA. 2011. Dairy Heifer Raiser, 2011. Accessed Mar. 2021. https: //www.aphis.usda.gov/animal_health/nahms/dairy/downloads dairyheifer11/HeiferRaiser_1.pdf.

van Houtert, M. F. J. 1993. The production and metabolism of volatile fatty acids by ruminants fed roughages: A review. Anim. Feed Sci. Technol. 43:189-225. https://doi.org/10.1016/0377-8401(93)90078 $-\mathrm{X}$.

Waldroup, P. W., and C. A. Fritts. 2005. Evaluation of separate and combined effects of choline and betaine in diets for male broilers. Int. J. Poult. Sci. 4:442-448. https://doi.org/10.3923/ijps.2005.442 448 .

Weitkunat, K., S. Schumann, D. Nickel, S. Hornemann, K. J. Petzke, M. B. Schulze, A. F. Pfeiffer, and S. Klaus. 2017. Odd-chain fatty acids as a biomarker for dietary fiber intake: A novel pathway for endogenous production from propionate. Am. J. Clin. Nutr. 105:1544-1551. https://doi.org/10.3945/ajcn.117.152702.

Yáñez-Ruiz, D. R., L. Abecia, and C. J. Newbold. 2015. Manipulating rumen microbiome and fermentation through interventions during early life: A review. Front. Microbiol. 6:1133. https://doi.org/10 $.3389 /$ fmicb.2015.01133.

Yunta, C., M. Terré, and A. Bach. 2015. Short- and medium-term changes in performance and metabolism of dairy calves offered different amounts of milk replacers. Livest. Sci. 181:249-255. https:/ /doi.org/10.1016/j.livsci.2015.09.008.

Zeisel, S. H., and K.-A. da Costa. 2009. Choline: An essential nutrient for public health. Nutr. Rev. 67:615-623. https://doi.org/10.1111/ j.1753-4887.2009.00246.x.

\section{ORCIDS}

L. N. Leal $\odot$ https://orcid.org/0000-0002-7798-3995

J. Doelman ( https://orcid.org/0000-0002-3328-8042

B. R. Keppler ๑ https://orcid.org/0000-0003-4097-7775

M. A. Steele @ https://orcid.org/0000-0001-6941-6205

J. Martín-Tereso (® https://orcid.org/0000-0002-6757-4629 